\title{
EFFECTS OF CALCIUM CHELATION ON DIGITALIS-INDUCED CARDIAC ARRHYTHMIAS
}

\author{
BY \\ PAUL SZEKELY AND N. A. WYNNE \\ From the Cardiovascular Department, Newcastle General Hospital, and the Department of Physiology, King's College, \\ University of Durham \\ Received November 19, 1962
}

Several studies have already shown that cardiac arrhythmias caused by digitalis can be abolished by the induction of hypocalcæmia (Page and Real, 1955; Smith and Grinnell, 1955; Gubner and Kallman, 1957; Kabakow and Brothers, 1958; Surawicz et al., 1959; Cohen et al., 1959; Rosenbaum, Mason, and Seven, 1960; Surawicz, 1960; Soffer, Toribara, and Sayman, 1961). The rationale of inducing hypocalcæmia as an anti-arrhythmic measure is based on experimental and clinical observations relating to the direct myocardial action of calcium and to the interaction between calcium, potassium, and digitalis. Low calcium concentration decreases myocardial irritability (Brooks et al., 1955) and it also increases the intracellular potassium concentration (Rosenbaum et al., 1960). There is also a synergistic action between calcium and digitalis, which was observed in the presence of digitalis intoxication (Nalbandian et al., 1957). The present study was undertaken in order to assess the value of induced hypocalcæmia in the management of cardiac arrhythmias caused by digitalis.

\section{Material AND Methods}

Forty-eight experiments were carried out under general anæsthesia on 46 cats and 2 dogs. Cardiac arrhythmia was induced by the intravenous administration of tincture of digitalis as previously described (Szekely and Wynne, 1951). Clinical studies were made in four patients in whom it was assumed with reasonable certainty that the ectopic rhythm was a manifestation of digitalis toxicity. The paucity of the clinical cases was entirely due to the fact that we have succeeded in recent years in considerably reducing the incidence of digitalis toxicity by paying close attention to the great variations in individual digitalis requirements and to the state of the electrolytes, together with the judicious use of oral potassium and/or procaine amide as prophylactic anti-arrhythmic agents (Szekely and Wynne, 1961).

Hypocalcæmia was induced by ethylene-diamine tetra-acetic acid (EDTA). Between 10 and $20 \mathrm{mg} . / \mathrm{kg}$. body weight of disodium EDTA were given intravenously at five-minute intervals. Regular serum calcium estimations were not carried out in this study, because (1) it has already been reliably established that EDTA is most effective in producing a rapid, though transient hypocalcæmia (Popovici et al., 1950; Bessman and Doorenbos, 1957; Surawicz, 1960); (2) in the context of the present experiments the prolongation of the Q-T interval in the electrocardiogram can be regarded as a reliable sign of the existence of a hypocalcæmic state (Barker, Johnston, and Wilson, 1937; Somerville, 1951); and (3) there is evidence of a poor quantitative relation between the degree of hypocalcæmia and the clinical response (Cohen et al., 1959; Surawicz et al., 1959).

\section{RESULTS}

Effects of EDTA on the Normal Electrocardiogram. Disodium EDTA produced consistently a prolongation of the Q-T interval which was already evident after the first dose. There was as a rule an initial increase in the amplitude of the $T$ waves followed by lowering and occasionally by inversion. In some experiments alternation of the $T$ waves was observed. When the total dose 


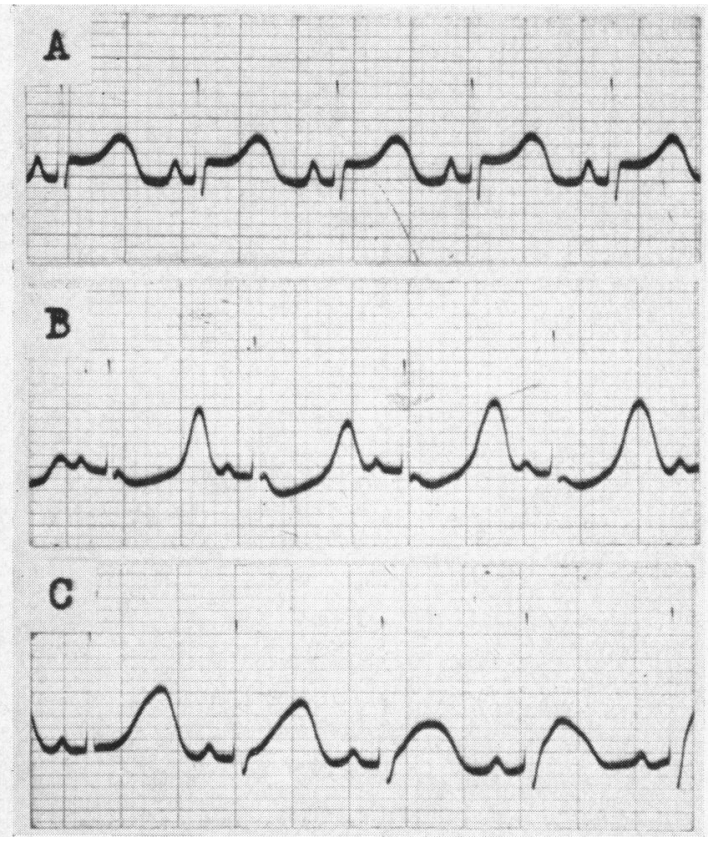

FIG. 1.-Cat, weight $1.5 \mathrm{~kg}$. Lead II. (A) Initial tracing. (B) After $36 \mathrm{mg}$. $/ \mathrm{kg}$. of disodium EDTA. Prolongation of Q-T interval. (C) After $100 \mathrm{mg}$. calcium gluconate. Shortening of $\mathrm{Q}-\mathrm{T}$ interval.

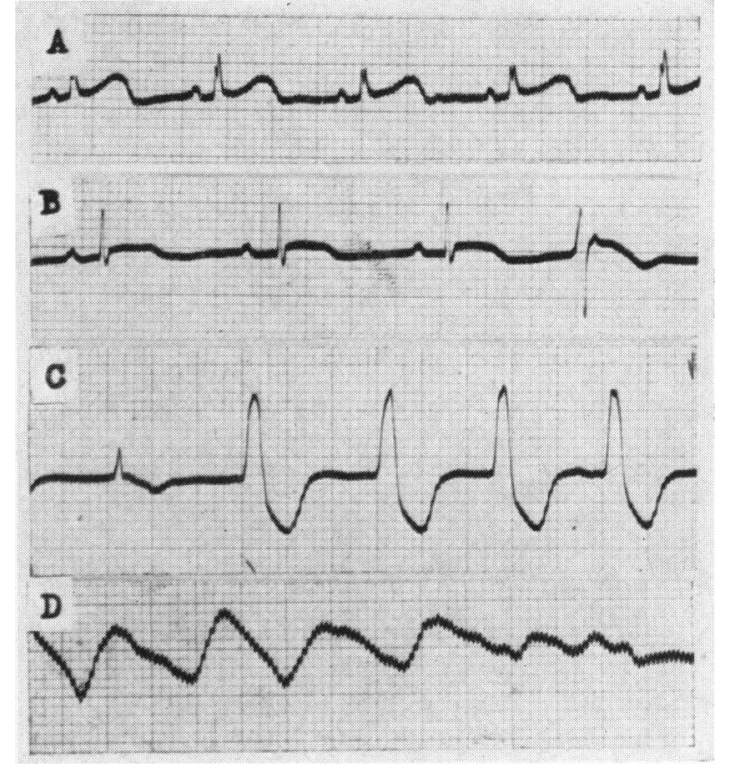

FIG. 2.-Cat, weight $2 \cdot 2 \mathrm{~kg}$. Lead II. Concomitant administration of digitalis and EDTA (one-third of the calculated lethal dose of digitalis and $10 \mathrm{mg} . / \mathrm{kg}$. of disodium EDTA per dose). (A) Initial tracing. (B) Extrasystoles first appeared after four-thirds of the calculated lethal dose of digitalis. (C) Ventricular tachycardia after six-thirds of the calculated lethal dose of digitalis. (D) Ventricular fibrillation after seven-thirds of the calculated lethal dose of digitalis. The usual sequence of events seen in experimental digitalis intoxication, but after significantly larger doses than when digitalis is given without EDTA.

of EDTA exceeded $100 \mathrm{mg}$./kg. bizarre ventricular complexes and extrasystoles appeared and further doses resulted in ventricular fibrillation and death of the animal.

Intravenous calcium gluconate promptly shortened the prolonged Q-T interval induced by EDTA (Fig. 1). However, calcium was ineffective in bringing back to normal the grossly altered ventricular complexes or reversing ventricular fibrillation resulting from large doses of EDTA.

Digitalis and EDTA. These experiments were arranged in two groups. In the first group digitalis was given until the appearance of cardiac arrhythmias and then the effect of EDTA was observed. In the second group digitalis and EDTA were given concomitantly with a view to ascertaining the digitalis dose required to produce ectopic beats.

Digitalis-induced ventricular extrasystoles and ventricular tachycardia were invariably abolished by disodium EDTA. The effect was often transient. However, in over half of the experiments the arrhythmia did not recur during a period of observation of up to one hour. The result of such an experiment is shown in Fig. 3.

In previous experiments in cats it was established that the average lethal dose of digitalis was $1 \mathrm{ml}$. tincture of digitalis per $\mathrm{kg}$. body weight, and that ectopic beats appeared as a rule after the administration of two-thirds of the lethal dose (Szekely and Wynne, 1951). When digitalis and EDTA were given concomitantly the average dose of digitalis necessary to produce ectopic beats and eventually death from ventricular fibrillation was twice as large as when digitalis was given alone (Fig. 2).

The tracing reproduced in Fig. 4 is from a 60 -year-old man with advanced rheumatic heart 


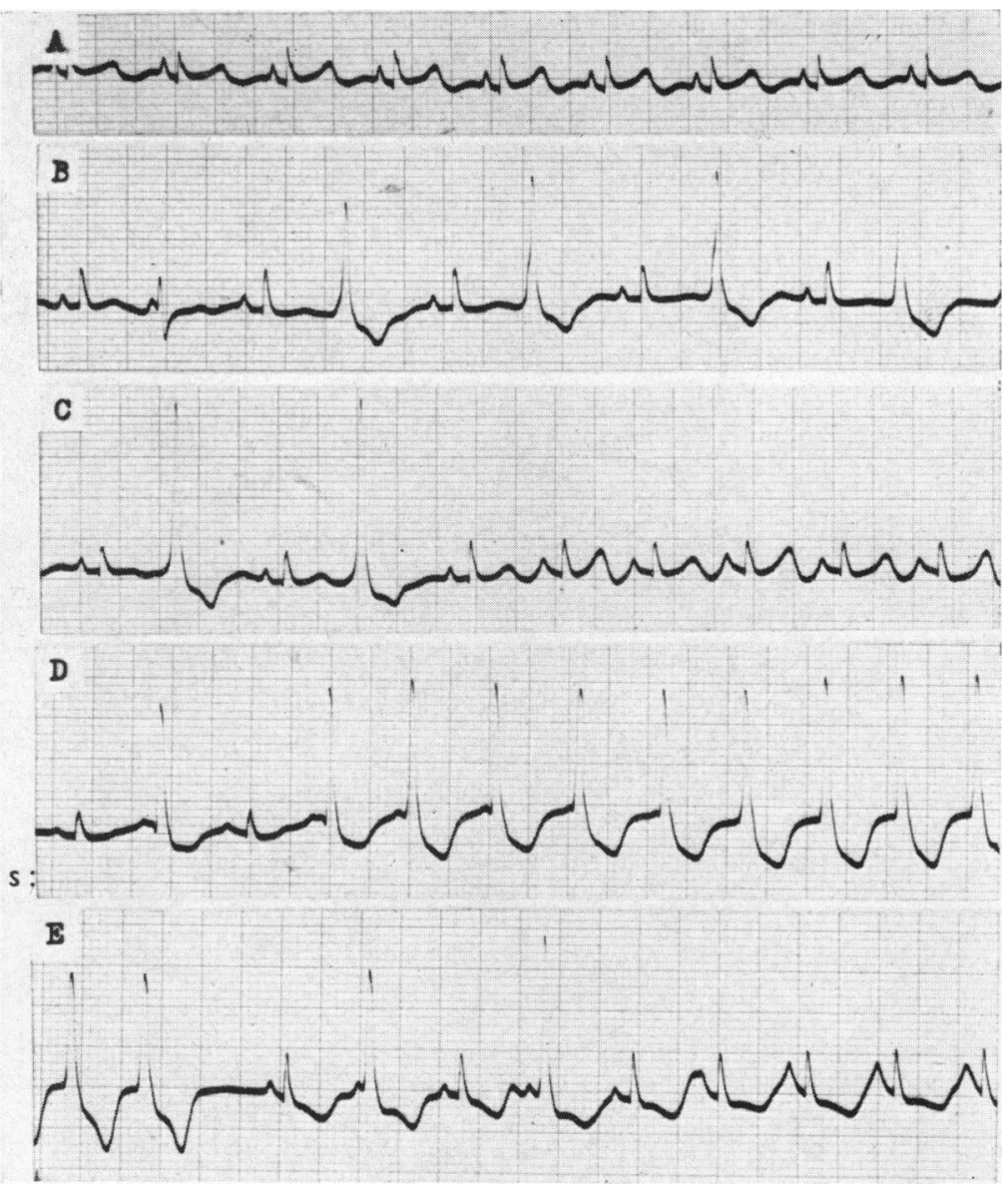

FIG. 3.-Cat, weight $2.5 \mathrm{~kg}$. Lead II. (A) Initial tracing. (B) After two-thirds of the calculated lethal dose of digitalis. Extrasystolic bigeminy. (C) After $12 \mathrm{mg} . / \mathrm{kg}$. of disodium EDTA. Extrasystoles abolished. (D) Further digitalization (additional two-thirds of the calculated lethal dose) resulted in return of ventricular extrasystoles followed by ventricular tachycardia. (E) After further $36 \mathrm{mg} . / \mathrm{kg}$. of disodium EDTA. Sinus rhythm restored. The two ventricular extrasystoles after the administration of EDTA show a longer coupling interval than those in (B) before EDTA was given.

disease. It shows atrial fibrillation and extrasystolic bigeminy after digitalization. The extrasystoles were abolished by the intravenous injection of $1 \mathrm{~g}$. disodium EDTA. Oral potassium was then commenced and there was no recurrence of the ectopic beats. In another patient with rheumatic heart disease and digitalis-induced extrasystolic bigeminy the ectopic beats disappeared after 2 g. disodium EDTA.

Fig. 5 shows an episode of ventricular tachycardia in a 54-year-old man with acute cardiac infarction and heart failure who had been receiving $0.75 \mathrm{mg}$. of digoxin daily for three days. Sinus rhythm was restored with $2 \mathrm{~g}$. of disodium EDTA and the ectopic rhythm did not recur. In another patient with an acute cardiac infarction and heart failure, who had received a total of $2.5 \mathrm{mg}$. of digoxin in four days, an episode of ventricular tachycardia was terminated by $2 \mathrm{~g}$. disodium EDTA.

The S-T segment depression in the cardiogram due to digitalis was reversed by disodium EDTA and such an effect is illustrated in Fig. 6. 


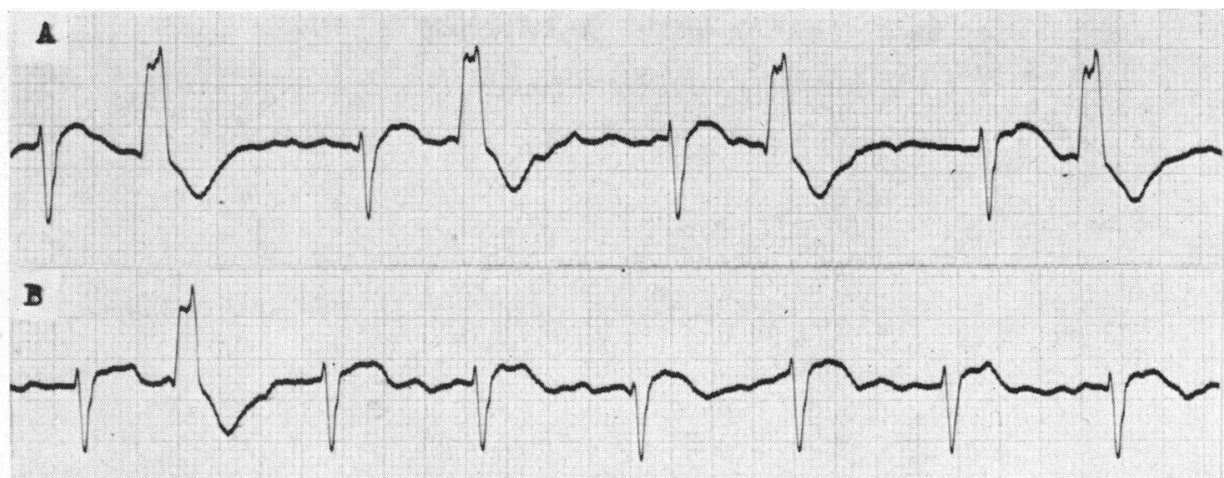

FIG. 4.-60-year-old man with rheumatic heart disease. Lead III. (A) Atrial fibrillation with digitalis-induced extrasystolic bigeminy. (B) Extrasystoles abolished with 1 g. of disodium EDTA.
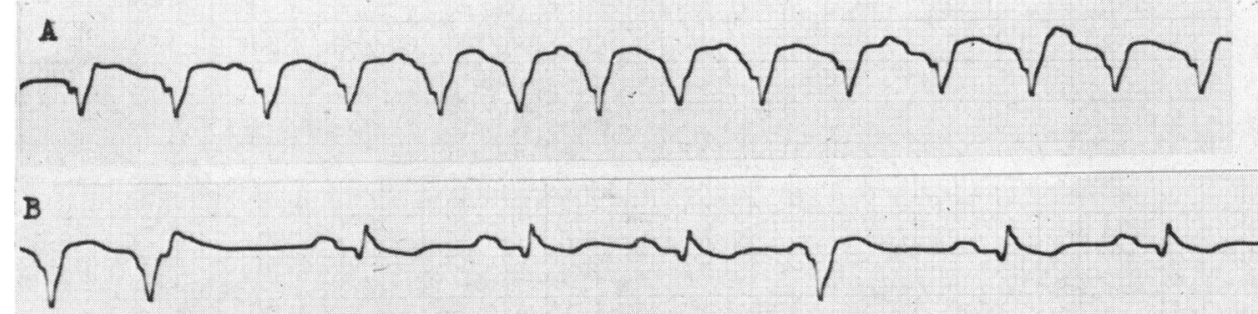

FIG. 5.-54-year-old man with acute cardiac infarction and heart failure. Lead II. (A) Ventricular tachycardia after digitalization. (B) Sinus rhythm restored with $2 \mathrm{~g}$. of disodium EDTA.

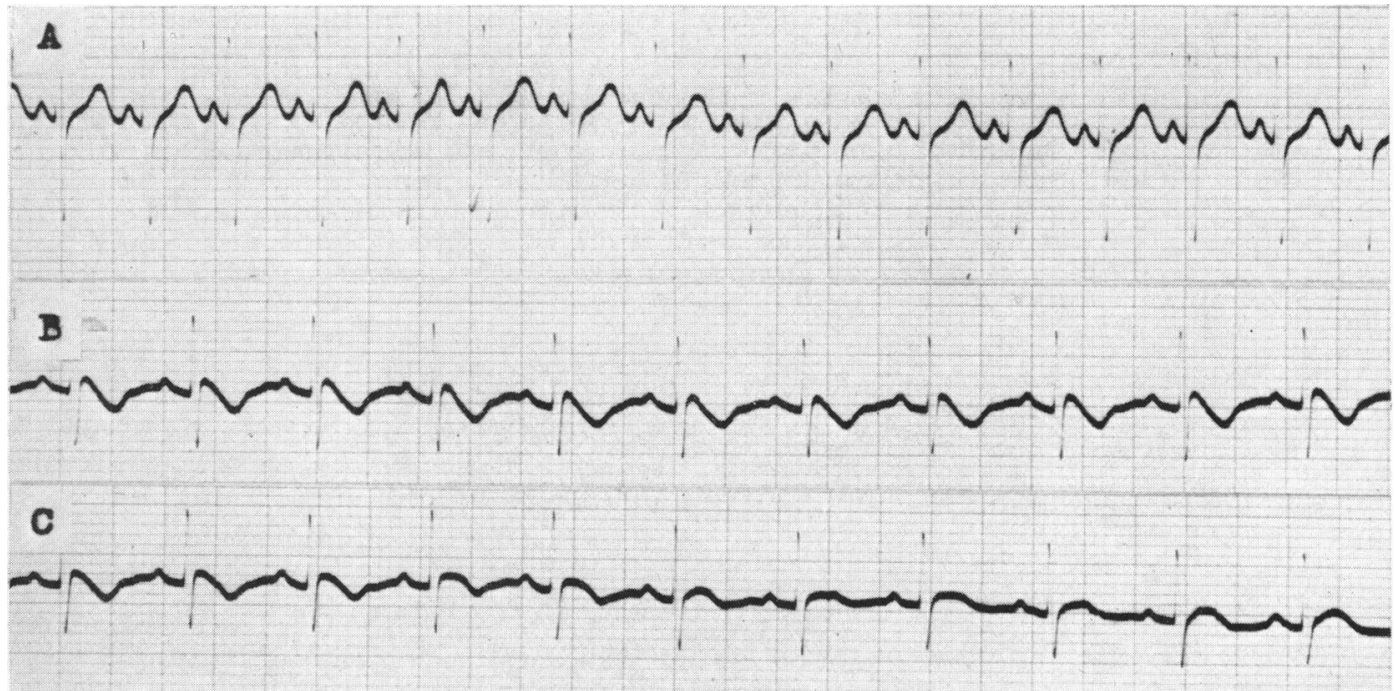

FIg. 6.-Cat, weight $1.7 \mathrm{~kg}$. Lead II. (A) Initial tracing. (B) After one-third of the calculated lethal dose of digitalis. Depression of S-T segment and T wave change. (C) After $12 \mathrm{mg}$. $/ \mathrm{kg}$. of disodium EDTA. Reversion of the electrocardiographic pattern of digitalis effect. 


\section{Discussion}

The experimental observations and the scanty clinical results presented in this paper show that disodium EDTA can be successfully used in the treatment of digitalis-induced cardiac arrhythmias.

Although EDTA has a direct cardio-depressant action, especially when given in large doses (Rothlin, Taeschler, and Cerletti, 1954; Kabakow and Brothers, 1958), it is believed that its antiarrhythmic effect is based on the induction of a transient hypocalcæmic state. Surawicz et al. (1959) found in several patients that after successful control of the cardiac arrhythmia by EDTA the ectopic beats reappeared promptly after the intravenous administration of calcium. They also observed that ventricular extrasystoles when still present after the injection of EDTA showed a longer coupling interval than those before EDTA. They are of the opinion that the longer coupling interval after EDTA, together with the prolonged electrical systole, indicates a prolongation of the refractory period of the ventricular myocardium, which is ultimately responsible for the antiarrhythmic action.

In the experience of Brothers and Kabakow (1957) EDTA had no effect on cardiac arrhythmias not caused by digitalis. Jick and Karsh (1959) arrived on the whole at the same conclusion and they suggested that a positive response to the administration of EDTA was strongly suggestive of digitalis intoxication while a negative result cast considerable doubt on its presence. Eliot and Blount (1961) also found EDTA much more reliable in digitalis-induced cardiac arrhythmias than in those of other origin. On the other hand, several reports show that EDTA is equally effective in abolishing ectopic beats not due to digitalis (Cohen et al., 1959; Surawicz et al., 1959; Surawicz, 1960; Soffer et al., 1961; Corday et al., 1962).

There is evidence that EDTA also reverses the depressant effects of digitalis. Bernstein, Neschis, and Collini (1959) observed a patient with massive digitalis poisoning exhibiting prolonged periods of sinus arrest, who responded favourably to EDTA therapy.

We were able to show that EDTA exerted a protective action against digitalis intoxication when it was given concomitantly with digitalis. In these experiments cardiac arrhythmias appeared only after much larger doses of digitalis, and the lethal dose of digitalis was also significantly larger than when digitalis was given alone. Such a protective effect of hypocalcæmia was previously reported by Baker (1947), Gubner and Kallman (1957), and Lown, Black, and Moore (1960).

It has been possible to reverse the electrocardiographic pattern of digitalis effect (S-T segment and T wave pattern) by EDTA (Page and Real, 1955; Brothers and Kabakow, 1957; Soffer et al., 1961). Our own observations are in agreement with these findings. In this connexion it is of interest that in the experience of Brothers and Kabakow (1957) S-T segment depression and T wave changes due to left ventricular hypertrophy or coronary insufficiency were unaffected by EDTA.

The effect of EDTA is often only transient, which is probably due to the rapid return of the serum calcium level to normal (Jick and Karsh, 1959). Nevertheless, EDTA is valuable as an initial therapy in emergency situations and it can be combined with a slower and more conventional oral potassium therapy as pointed out by Rosenbaum et al. (1960).

No significant toxic manifestations have been observed in patients treated with EDTA. Rosenbaum et al. (1960) state that $3 \mathrm{~g}$. of disodium EDTA can be given intravenously over a 20 -minute period with safety. However, Sapeika (1954) warns that the administration of the drug can lead to a sudden severe depression of the myocardium with a severe fall of the blood pressure, especially when large doses are injected rapidly.

Cardiac arrhythmias precipitated by digitalis should be recognized promptly, because continuation of digitalis therapy is likely to aggravate the cardiac condition and can also lead to ventricular fibrillation. We concur with the observations of Jick and Karsh (1959) and Rosenbaum et al. (1960) that disodium EDTA has a particular therapeutic value in those cases of digitalis intoxication in which a rapid response is desired and that this therapy can be usefully combined with the oral administration of potassium. 


\section{SUMMARY}

Disodium EDTA abolished ventricular extrasystoles and ventricular tachycardia caused by digitalis in the experimental animal and in man. When administered concomitantly with digitalis it exerted a protective action against digitalis toxicity in the experimental animal.

Disodium EDTA reversed the electrocardiographic pattern of digitalis effect.

Disodium EDTA seems to be a valuable agent in the management of digitalis-induced cardiac arrhythmias, especially in those in which a rapid response is desired. However, the effect may be only transient and it is therefore advisable to combine this form of therapy with oral potassium and/or procaine amide.

\section{REFERENCES}

Baker, J. B. E. (1947). The influence of calcium and potassium ions on the toxicity of ouabain. Brit. J. Pharmacol., $2,259$.

Barker, P. S., Johnston, F. D., and Wilson, F. N. (1937). The duration of systole in hypocalcemia. Amer. Heart J., $14,82$.

Bernstein, M. S., Neschis, M., and Collini, F. (1959). Treatment of acute massive digitalis poisoning by administration of a chelating agent. New Engl. J. Med., 261, 961.

Bessman, S. P., and Doorenbos, N. J. (1957). Chelation. Ann. intern. Med., 47, 1036.

Brooks, C. M., Hoffman, B. F., Suckling, E. E., and Orias, O. (1955). Excitability of the Heart, p. 298. Grune and Stratton, New York.

Brothers, M. J., and Kabakow, B. (1957). Effects of induced hypocalcemia upon the electrocardiographic manifestations of digitalis. Circulation, 16, 864 .

Cohen, B. D., Spritz, N., Lubash, G. D., and Rubin, A. L. (1959). Use of a calcium chelating agent (NaEDTA) in cardiac arrhythmias. Circulation, 19, 918.

Corday, E., Irving, D. W., Gold, H., Bernstein, H., and Jaffe, H. (1962). Recent advances in the treatment of arrhythmias and conduction defects. Amer. Heart J., 64, 126.

Eliot, R. S., and Blount, S. G. (1961). Calcium, chelates, and digitalis. A clinical study. Amer. Heart J., $62,7$.

Gubner, R. S., and Kallman, H. (1957). Treatment of digitalis toxicity by chelation of serum calcium. Amer. J. med. Sci., 234, 136.

Jick, S., and Karsh, R. (1959). The effect of calcium chelation on cardiac arrhythmias and conduction disturbances. Amer. J. Cardiol., 4, 287.

Kabakow, B., and Brothers, M. J. (1958). The effects of induced hypocalcemia on myocardial irritability and conductivity. Arch. intern. Med., 101, 1029.

Lown, B., Black, H., and Moore, F. D. (1960). Digitalis, electrolytes and the surgical patient. Amer. J. Cardiol., 6, 309.

Nalbandian, R. M., Gordon, S., Campbell, R., and Kaufman, J. (1957). A new, quantitative digitalis tolerance test based upon the synergism of calcium and digitalis. Amer. J. med. Sci., 233, 503.

Page, E., and Real, J. D. (1955). Interrelationships between cardiac effects of ouabain, hypocalcemia and hyperkalemia. Circulat. Res., 3, 501.

Popovici, A., Geschickter, C. F., Reinovsky, A., and Rubin, M. (1950). Experimental control of serum calcium levels in vivo. Proc. Soc. exp. Biol. (N.Y.), 74, 415.

Rosenbaum, J. L., Mason, D., and Seven, M. J. (1960). The effect of disodium EDTA on digitalis intoxication. Amer. J. med. Sci., $240,77$.

Rothlin, E., Taeschler, M., and Cerletti, A. (1954). Beitrag zur biologischen Wirkung von komplexgebundenem Calcium. Schweiz. med. Wschr., 84, 1286.

Sapeika, N. (1954). Antagonism of digitalis action by ethylenediamine tetraacetic acid. Arch. int. Pharmacodyn., 97, 373.

Smith, P. W., and Grinnell, E. H. (1955). Effect of di-potassium ethylenediamine tetraacetate on digitalis-produced cardiac arrhythmia. Fed. Proc., 14, 387.

Soffer, A., Toribara, T., and Sayman, A. (1961). Myocardial responses to chelation. Brit. Heart J., 23, 690

Somerville, W. (1951). The effect of potassium and calcium on the electrocardiogram. Postgrad. med.J., $27,296$.

Surawicz, B. (1960). Use of the chelating agent, EDTA, in digitalis intoxication and cardiac arrhythmias. Progr. cardiovasc. Dis., $2,432$.

- MacDonald, M. G., Kaljot, V., and Bettinger, J. C. (1959). Treatment of cardiac arrhythmias with salts of ethylenediamine tetraacetic acid (EDTA). Amer. Heart J., 58, 493.

Szekely, P., and Wynne, N. A. (1951). The effects of magnesium on cardiac arrhythmias caused by digitalis. Clin. Sci., 10, 241.

-, (1961). The therapeutic-toxic ratio in digitalization. Biochem. Pharmacol., 8, 107. 